\title{
ARTICLE
}

Epidemiology and population health

\section{Comparison of the associations between non-traditional and traditional indices of adiposity and cardiovascular mortality: an observational study of one million person-years of follow-up}

\author{
Anne Pernille Ofstad $\mathbb{D}^{1,2} \cdot$ Christine Sommer $\mathbb{D}^{3} \cdot$ Kåre I Birkeland $^{4,5} \cdot$ Marit Rokne Bjørgaas $^{6,7} \cdot$ Jon Michael Gran $^{8}$. \\ Hanne Løvdal Gulseth ${ }^{3}$. Odd Erik Johansen ${ }^{1,2}$
}

Received: 12 February 2018 / Revised: 2 September 2018 / Accepted: 30 January 2019 / Published online: 29 March 2019

(c) The author(s) 2019. This article is published with open access

\begin{abstract}
Background/objective The most widely used adiposity index, body mass index (BMI), is not optimal to evaluate cardiovascular $(\mathrm{CV})$ risk associated with overweight and obesity. We aimed to explore the association between traditional and nontraditional adiposity indices and CV mortality, and compare their discriminative ability for CV death.

Methods We studied participants (age 19-79 years, BMI $\geq 18.5 \mathrm{~kg} / \mathrm{m}^{2}$ ) from the population-based Norwegian NordTrøndelag Health Study 2 (HUNT 2). Traditional indices explored were BMI, waist circumference (WC) and waist- to-hip ratio, whereas non-traditional were estimated total body fat (eTBF), which is a sex-specific fat $\%$-index, index of central

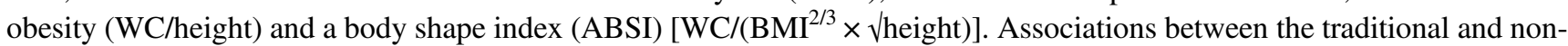
traditional indices and CV death, obtained from the Norwegian Cause of Death Registry, were explored by Cox proportional hazard regression, and the indices' discriminative ability by Harrell's $C$ statistics.

Results Baseline assessments were done from 1995 to 1997 and the population ( $n=61,016,52 \%$ women) was observed for $17.7 \pm 4.2$ years (until 2016), yielding 1,080,473.6 person-years of follow-up. Thirteen thousand one hundred and ninety five (21.6\%) subjects died, of whom 4908 (37.2\%) died from CV causes. Across genders, eTBF had the strongest association to CV death (unadjusted hazard ratios [HRs] 4th vs. 1st quartile in women and men 13.38 [95\% confidence interval (CI): 11.05-16.22] and 9.32 [8.03-10.81], respectively), together with index of central obesity in women and ABSI in men. The other indices showed weaker associations, in particular BMI in men: 1.73 [1.56-1.93]. Age adjustment attenuated the associations, but the pattern remained. In concordance with this, $C$-statistics was $C=0.725$ [0.713-0.737] in women and 0.711 [0.701-0.721] in men for eTBF, and $C=0.622$ [0.610-0.634] in women and 0.551 [0.541-0.562] in men for BMI. Conclusion eTBF, a sex-specific total body fat index, was more strongly associated with CV death than other adiposity indices and may be a suitable clinical tool for assessment of obesity-associated CV risk.
\end{abstract}

These authors contributed equally: Hanne Løvdal Gulseth, Odd Erik Johansen

Supplementary information The online version of this article (https:// doi.org/10.1038/s41366-019-0353-9) contains supplementary material, which is available to authorised users.

Anne Pernille Ofstad

Annepernille@hotmail.com

1 Department of Medical Research, Bærum Hospital, Vestre Viken Hospital Trust, Gjettum, Norway

2 Medical Department, Boehringer Ingelheim Norway, Asker, Norway

3 Department of Endocrinology, Morbid Obesity and Preventive Medicine, Oslo University Hospital, Oslo, Norway

4 Department of Transplantation Medicine, Oslo University Hospital, Rikshospitalet, Norway

\section{Introduction}

The prevalence and disease burden of overweight and obesity is increasing, and data from 1990 to 2015 suggest that obesity is related to nearly four million deaths globally,

5 Faculty of Medicine, University of Oslo, Oslo, Norway

6 Department of Clinical and Molecular Medicine, Faculty of Medicine and Health Sciences, NTNU, Norwegian University of Science and Technology, Trondheim, Norway

7 Department of Endocrinology, St. Olav's Hospital, Trondheim University Hospital, Trondheim, Norway

8 Oslo Centre for Biostatistics and Epidemiology, Oslo University Hospital and University of Oslo, Oslo, Norway 
of which cardiovascular (CV) deaths account for nearly $70 \%$ [1]. Therefore, the various scientific societies recommend to avoid unhealthy fat accumulation for optimal health in most people [2].

Body mass index (BMI) is the most widely used standardised index to define normal weight, overweight and obesity in clinical practice [3]. BMI is easy to use, but it does not distinguish between lean body mass and fat mass and its distribution (visceral vs. subcutaneous), and it does not account for biological gender differences in fat function and distribution. Fat mass and its distribution, particularly abdominal fat, is strongly associated with adverse outcomes and data suggest that intra-abdominal (visceral) adipose tissue may be a primary driver of the cardiometabolic complications of obesity [4].

Most epidemiological studies that include measures of validated indices of body fat or body fat distribution show that these appear to predict CV complications more precisely than BMI [5-8]. Traditional indices of adiposity include waist circumference (WC) and waist-to-hip ratio (WHR), whereas non-traditional, and less studied, indices include WHR (often called index of central obesity, ICO) [7, 9], a body shape index (ABSI) reflecting abdominal visceral fat [10] and estimated total body fat (eTBF), which is based on the Young Man's Christian Association's (YMCA) gender-specific formulas [11, 12].

The aim of this study was to explore the associations of readily available non-traditional (eTBF, ABSI, ICO) and traditional (WC, WHR, BMI) anthropometric indices of fat and fat distribution with long-term CV mortality in the large population-based The Nord-Trøndelag Health Study 2 (HUNT 2) study, and to contrast their ability to predict CV mortality risk in order to identify the best adiposity index for routine clinical use.

\section{Materials and methods}

\section{Study population}

HUNT 2 was the second wave of the original HUNT study [13], a population-based multi-purpose health study in the ethnically homogenous county of Nord-Trøndelag, Norway. This population is considered representative of the total ethnic Norwegian population regarding demography, socio-economic factors, morbidity and mortality, including mortality from CV disease [14]. For HUNT 2, all residents 20 years or older were invited to a screening visit between August 1995 and July 1997. Subjects responded to a comprehensive health and lifestyle questionnaire and underwent a general health examination. Details of the protocol and study design have been described previously [14]. For the purpose of this study, we excluded individuals with BMI $<18.5 \mathrm{~kg} / \mathrm{m}^{2}$ and those with age $<19$ or $>79$ years.

\section{Anthropometric measures, indices of adiposity and laboratory assessments}

All exposures were assessed using standardised methodology. Body height and body weight were recorded with the participants wearing light clothes and no shoes. Height was measured to the nearest centimetre and weight to the nearest $0.5 \mathrm{~kg}$. Based on these measures, BMI was calculated as weight (in $\mathrm{kg}$ ) divided by the squared value of height (in $\mathrm{m}$ ). WC and hip circumferences were measured with a steel band to the nearest centimetre with the participant standing and with the arms hanging relaxed. The WC was measured horizontally at the height of the umbilicus, and the hip circumference was measured likewise at the thickest part of the hip [14].

ICO was calculated as WC/height [7, 9], WHR as WC/ hip circumference, eTBF by the sex-specific YMCA formulas (men: $100 \times(-98.42+[4.15 \times \mathrm{WC}$ (in.) $]-[0.082 \times$ weight (lbs)])/weight; females: $100 \times(-76.76+[4.15 \times$ WC $]-[0.082 \times$ weight $]) /$ weight $)[11,12]$ and ABSI as WC

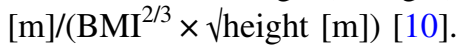

Systolic and diastolic blood pressure was measured three times and the mean of the two last measurements was used. All blood samples were drawn in the non-fasting state. Participants who either reported to have diabetes mellitus or who had a non-fasting blood glucose above $11.1 \mathrm{~mL} / \mathrm{L}$ at baseline (i.e. at inclusion in HUNT 2) were defined as having diabetes. CV comorbidities at baseline were selfreported by participants (previous myocardial infarction, episode of angina pectoris, or stroke), as were smoking habits ("no smoking", "former smoking" or "current daily smoking of cigarettes, cigars or pipe"). Education was categorised into having completed: primary school, 1-2 years of secondary school, high school, $<4$ years of college/ university or $>4$ years of college/university.

\section{Follow-up and outcome}

All participants enrolled in HUNT 2 (1995-1997) included in the present study were followed for CV mortality. Using the participants' unique personal identity number, HUNT 2 data were linked to the Norwegian Cause of Death Registry, to which all deaths in Norway are reported. Death from CV disease was defined according to the International Classification of Disease codes ICD-9: 390-459 for deaths before 2005 and ICD-10: 100-199 for deaths as of 1 January 2005. Subjects were followed until death or until 31 December 2015, whichever occurred first. 


\section{Informed consent and ethics}

All participants in HUNT 2 gave written informed consent and the study was approved by the Regional Committee for Medical and Health Research Ethics and by the Norwegian Data Inspectorate. The present study and protocol were approved by the Regional Committee for Medical and Health Research Ethics in 2016.

\section{Statistical analyses}

All adiposity indices were categorised into sex-specific quartiles. We used Cox proportional hazard models to explore the associations between the different categories of the indices of adiposity and CV death, with the lowest quartile as the reference category. The proportional hazard assumption was assessed by a test based on Schoenfeld's residuals. We analysed data from men and women separately in crude models as well as in models adjusted for age. To address potential confounding factors, we conducted sensitivity analyses in which we excluded participants with known CV disease, diabetes or current smoking, respectively.

Harrell's $C$-statistics were calculated based on the Cox proportional hazard regression models to assess individual indices' discrimination [15]. C- index is developed for survival analysis and describes the adiposity index' ability to distinguish between persons with longer eventfree survival and those with shorter event-free survival within a given time horizon [16]. The $\mathrm{C}$-index ranges from a minimum of 0.5 (no discriminatory accuracy) to a theoretical maximum of 1.0 (perfect discrimination). To explore the continuous relationship between the adiposity indices and $\mathrm{CV}$ death, we used fractional polynominal plots displaying the $\mathrm{HR}$ for $\mathrm{CV}$ death for each unit of the adiposity index, for men and women separately. Owing to very low number of participants in the highest ranges of the indices, the graphical displays exclude the $0.5 \%$ highest and lowest values for men and women for each adiposity index. We used sex-specific $z$-scores to compare HR for $\mathrm{CV}$ death across different adiposity indices.

We analysed relationships between $\mathrm{CV}$ mortality and BMI, WC, ICO, WHR, eTBF and ABSI by quartiles of adiposity indices, with the lowest quartile as the reference category. To reduce the influence of competing risk, we excluded those with age $\geq 80$ years and BMI $<18.5 \mathrm{~kg} / \mathrm{m}^{2}$, and due to gender differences in fat mass distribution/ function, we also investigated this relationship for women and men separately. Further, since age and frailty may influence the relationship, we also analysed the associations in two age strata: younger: 19-59 years vs. older: 60-79 years. Absolute risk of $\mathrm{CV}$ death was expressed as sex- specific incidence rates per 1000 patient year per quartile of the adiposity indices.

Analyses were performed using SPSS version 24.0 (SPSS Inc., Chicago, IL, USA), STATA version 14 (StataCorp, College Station, TX, USA), and R (R Core Team (2017). R: A language and environment for statistical computing. R Foundation for Statistical Computing, Vienna, Austria. URL https://www.R-project.org/). In all analyses, $p<0.05$ was considered significant.

\section{Results and discussion}

\section{Population characteristics}

Of 92,434 eligible subjects in Nord-Trøndelag County, 66,140 men and women $(71.2 \%)$ attended the screening. Excluding individuals with BMI $<18.5 \mathrm{~kg} / \mathrm{m}^{2}$ and not within age-span 19-79 years rendered 61,016 individuals (31,936 women, 29,080 men) to be included in this study, and baseline characteristics are given in Table 1. Male participants, as compared to female participants, had higher weight $(83.5 \pm 12.2$ vs. $70.8 \pm 12.5 \mathrm{~kg})$, systolic and diastolic blood pressure ( $140 \pm 19$ vs. $135 \pm 23$ and $82 \pm 12$ vs. $79 \pm 12 \mathrm{mmHg}$, respectively), $s$-triglycerides $(1.9 \pm 1.1 \mathrm{vs}$. $1.5 \pm 0.9 \mathrm{mmol} / \mathrm{L})$ and eGFR $(96.9 \pm 19.8$ vs. $92.7 \pm 20.9$ $\mathrm{mL} / \mathrm{min} / 1.73^{2}$ ). A larger proportion of men had previous CV disease ( 8.9 vs. $5.0 \%$ ). The mean BMI was similar in women and men, whereas the other adiposity indices differed between genders, with the most notable difference observed for the mean WC, which was higher in men $(91.9 \pm 9.3$ vs. $81.5 \pm 11.4 \mathrm{~cm})$, and the mean eTBF which was higher in women $(19.5 \pm 5.5$ vs. $27.3 \pm 7.4 \%)$. In both sexes, there were significant correlations between all adiposity indices (Supplementary Table 1).

\section{Relationships between adiposity indices and CV mortality}

The cohort was observed for CV mortality from 1 August 1995 until 31 December 2015, mean observational time $17.7 \pm 4.2$ (mean $\pm \mathrm{SD}$ ) years, corresponding to $1080,473.6$ person-years. In this period, 13,195 (21.6\%) participants died (6136 women, 7059 men), and of these, 4908 (37.2\%) died from CV causes (2214 women, 2694 men). Annualised CV mortality rates were 3.9/1000 person-years for women and 5.3/1000 person-years for men, with higher absolute risk of $\mathrm{CV}$ death with increasing levels of all adiposity indices (Table $2 \mathrm{a}$ and $2 \mathrm{~b}$ ).

All indices of adiposity, that is, general fat mass, abdominal fat mass and fat distribution were associated with $\mathrm{CV}$ mortality as illustrated in Fig. 1a-f, displaying HR for $\mathrm{CV}$ death by increasing levels of the individual adiposity 
Table 1 Baseline characteristics of the study population by sex

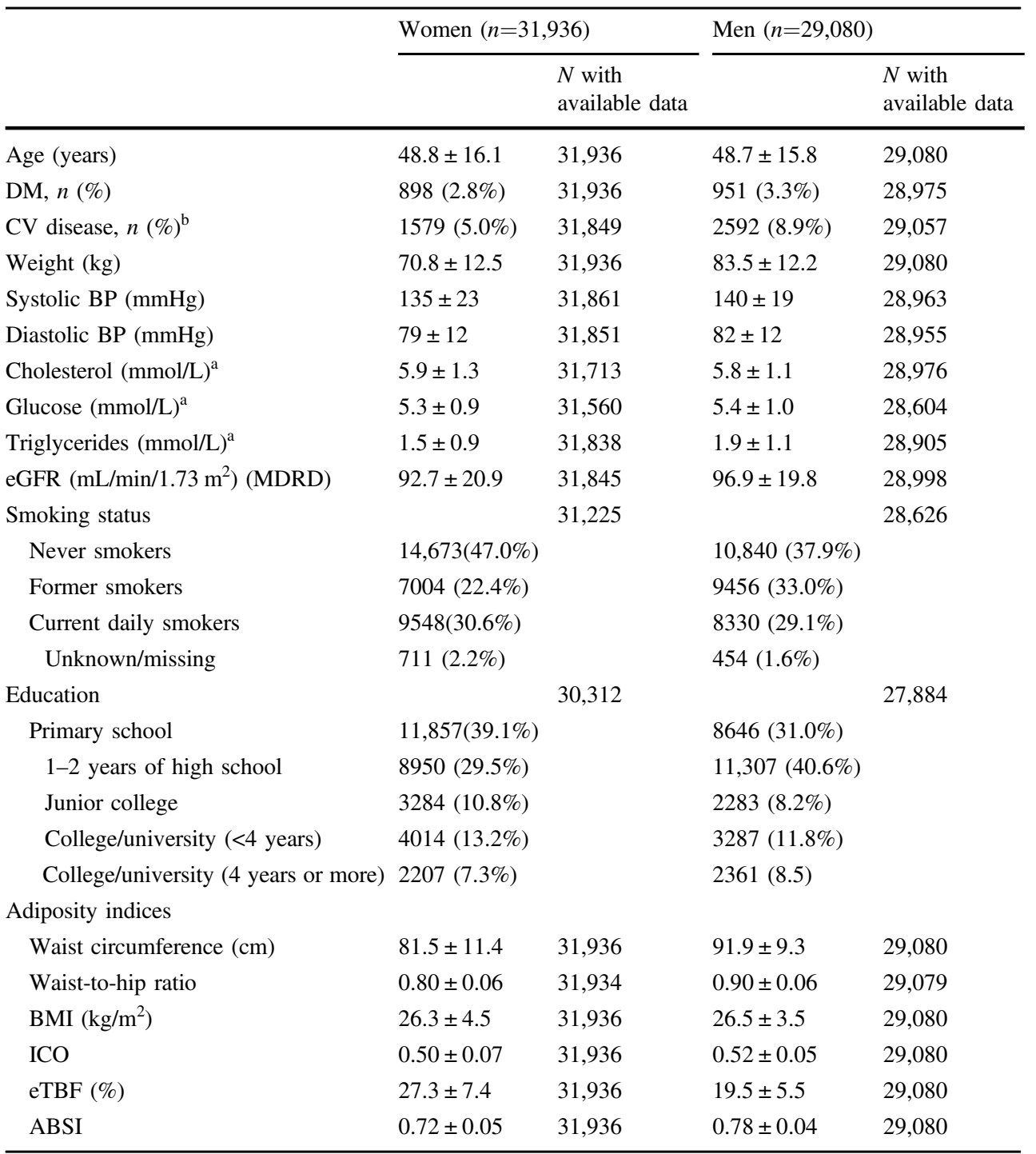

$S D$ standard deviation, $D M$ diabetes mellitus, $e G F R$ estimated glomerular filtration rate, $M D R D$ modified diet in renal disease, $B M I$ body mass index, $I C O$ index of central obesity, $e T B F$ estimated total body fat, $A B S I$ a body shape index

Data are given as mean plus/minus SD or proportions

aNon-fasting

${ }^{\mathrm{b}}$ Self-reported previous myocardial infarction, episode of angina pectoris or stroke at baseline index. The figures demonstrate a lower risk of CV death in the lowest ranges of the fat indices, and that the apparently most favourable levels of fat mass indices varied across sexes for most of the indices. For some indices, in particular eTBF in women, the risk of CV death seemed to level off at values corresponding to severe obesity. Of note is also the gender effect on CV mortality risk, in particular for eTBF, but also for WC and WHR. The CV mortality risk increases at lower levels of eTBF in men as compared to women, whereas for WC and WHR, the risk increases at slightly lower levels in women as compared to men.

The HR for CV death increased by quartiles of adiposity indices (Table $2 \mathrm{a}$ and $2 \mathrm{~b}$ ) in men as well as in women. In both genders, the non-traditional index eTBF showed the strongest association (e.g. 4th vs. 1st quartile HR in women 13.38 (95\% CI: 11.05-16.22) and in men HR 9.32 (8.0310.81). Of note is also the weaker association between the HR for CV death and traditional indices, in particular BMI in men. In an age-adjusted model (Table $2 \mathrm{a}$ and $2 \mathrm{~b}$ ), the magnitude of association was less for all indices, yet eTBF remained a strong index in men, whereas in women, WHR and eTBF appeared to be of equal strength. Sensitivity analyses excluding participants with high risk for $\mathrm{CV}$ death at baseline (known CV disease, diabetes and current smokers) did not alter the associations between the adiposity indices and $\mathrm{CV}$ death (data not shown). 
Table 2a Unadjusted and ageadjusted associations between quartiles of traditional and nontraditional adiposity indices and $\mathrm{CV}$ death for women

\begin{tabular}{|c|c|c|c|c|c|}
\hline & \multicolumn{5}{|l|}{ Women } \\
\hline & $\begin{array}{l}N \text { with } \\
\text { available data }\end{array}$ & $\begin{array}{l}N \text { of } \mathrm{CV} \\
\text { deaths }\end{array}$ & $\begin{array}{l}\text { Incidence rates per } \\
1000 \text { patient years }\end{array}$ & $\begin{array}{l}\text { Unadjusted HR } \\
(95 \% \mathrm{CI})\end{array}$ & $\begin{array}{l}\text { Age-adjusted } \\
\text { HR ( } 95 \% \text { CI) }\end{array}$ \\
\hline Waist $(\mathrm{cm})$ & 31,936 & 2214 & & & \\
\hline$\leq 73.0$ & 7464 & 192 & 1.36 & 1 & 1 \\
\hline $73.1-80.0$ & 8085 & 355 & 2.39 & $1.77(1.49-2.11)$ & $0.91(0.76-1.08)$ \\
\hline $80.1-88.0$ & 8549 & 681 & 4.47 & $3.35(2.85-3.93)$ & $0.97(0.82-1.14)$ \\
\hline$\geq 88.1$ & 7838 & 986 & 7.41 & $5.64(4.83-6.59)$ & $1.24(1.06-1.45)$ \\
\hline $\begin{array}{l}\text { Waist-to- hip } \\
\text { ratio }\end{array}$ & 31,934 & 2214 & & & \\
\hline$\leq 0.75$ & 8022 & 214 & 1.43 & 1 & 1 \\
\hline $0.76-0.79$ & 7960 & 410 & 2.78 & $1.97(1.67-2.32)$ & $1.12(0.95-1.32)$ \\
\hline $0.80-0.83$ & 7948 & 588 & 4.12 & $2.92(2.50-3.42)$ & $1.11(0.94-1.30)$ \\
\hline$\geq 0.84$ & 8004 & 1002 & 7.46 & $5.37(4.63-6.23)$ & $1.49(1.28-1.73)$ \\
\hline BMI (m/kg $\left.{ }^{2}\right)$ & 31936 & 2214 & & & \\
\hline$\leq 23.0$ & 8078 & 302 & 2.02 & 1 & 1 \\
\hline $23.1-25.5$ & 7951 & 398 & 2.74 & $1.36(1.17-1.58)$ & $0.87(0.75-1.01)$ \\
\hline $25.6-28.7$ & 7950 & 614 & 4.30 & $2.15(1.87-2.46)$ & $0.87(0.76-1.00)$ \\
\hline$\geq 28.8$ & 7957 & 900 & 6.54 & $3.30(2.90-3.76)$ & $1.06(0.93-1.20)$ \\
\hline $\mathrm{ICO}$ & 31,936 & 2214 & & & \\
\hline$\leq 0.44$ & 7996 & 140 & 0.92 & 1 & 1 \\
\hline $0.45-0.49$ & 7962 & 312 & 2.11 & $2.34(1.91-2.85)$ & $0.97(0.79-1.19)$ \\
\hline $0.50-0.54$ & 7983 & 630 & 4.44 & $4.95(4.12-5.95)$ & $1.02(0.85-1.23)$ \\
\hline$\geq 0.55$ & 7995 & 1132 & 8.49 & $9.68(8.12-11.55)$ & $1.28(1.07-1.53)$ \\
\hline eTBF $(\%)$ & 31,936 & 2214 & & & \\
\hline$\leq 21.8$ & 7984 & 116 & 0.76 & 1 & 1 \\
\hline $21.9-27.0$ & 7995 & 310 & 2.09 & $2.84(2.30-3.53)$ & $1.15(0.93-1.43)$ \\
\hline $27.1-32.2$ & 7978 & 559 & 3.89 & $5.31(4.34-6.49)$ & $1.13(0.93-1.39)$ \\
\hline$\geq 32.3$ & 7979 & 1229 & 9.46 & $13.38(11.05-16.22)$ & $1.54(1.26-1.87)$ \\
\hline ABSI & 31,936 & 2214 & & & \\
\hline$\leq 0.69$ & 7984 & 207 & 1.36 & 1 & 1 \\
\hline $0.70-0.72$ & 7984 & 324 & 2.20 & $1.62(1.36-1.93)$ & $0.92(0.77-1.09)$ \\
\hline $0.73-0.75$ & 7985 & 559 & 3.92 & $2.95(2.52-3.46)$ & $1.05(0.89-1.23)$ \\
\hline$\geq 0.76$ & 7983 & 1124 & 8.55 & $6.60(5.69-7.66)$ & $1.14(1.14-1.15)$ \\
\hline
\end{tabular}

$C V$ cardiovascular, $H R$ hazard ratio, $C I$ confidence interval, $W H R$ waist-to-hip ratio, $B M I$ body mass index, $I C O$ index of central obesity, $e T B F$ estimated total body fat, $A B S I$ a body shape index
Across gender and age strata (Table $3 \mathrm{a}$ and $3 \mathrm{~b}$ ), all adiposity indices were related to $\mathrm{CV}$ death, but the HRs were somewhat higher in the younger age group, also after age adjustment. Regardless of age stratum, BMI showed the weakest association with CV death, whereas eTBF and ABSI appeared to show the strongest association. After age adjustment however, in the elderly, all indices except BMI seemed to be associated with $\mathrm{CV}$ death by similar magnitude.

The discriminative ability of the different indices as expressed by $C$-statistics is shown in Table 4 . In both women and men, the discriminative ability of eTBF was robust $(>0.7)$ and appeared to best capture the risk for $\mathrm{CV}$ death together with ICO in women and ABSI in men. When analysing sex-specific $z$-scores by individual adiposity indices, both eTBF and ABSI were strongly associated with CV death (Fig. 2).

In this large, population-based study with observation of individuals for more 17 years comprising more than one million person-years, we found that the non-traditional adiposity index eTBF was the strongest discriminator of CV death in both men and women. This index discriminated better than the traditional indices (BMI, WC and WHR), and on par with ICO in women and ABSI in men. To our knowledge, this is the first study to assess the discriminative property of the sex-specific adiposity index eTBF, a new 
Table $2 \mathrm{~b}$ Unadjusted and ageadjusted associations between quartiles of traditional and nontraditional adiposity indices and $\mathrm{CV}$ death for men

\begin{tabular}{|c|c|c|c|c|c|}
\hline & \multicolumn{5}{|l|}{ Men } \\
\hline & $\begin{array}{l}N \text { with } \\
\text { available }\end{array}$ & $\begin{array}{l}N \text { of } \mathrm{CV} \\
\text { deaths }\end{array}$ & $\begin{array}{l}\text { Incidence rates per } \\
1000 \text { patient years }\end{array}$ & $\begin{array}{l}\text { Unadjusted HR } \\
(95 \% \mathrm{CI})\end{array}$ & $\begin{array}{l}\text { Age-adjusted HR } \\
(95 \% \mathrm{CI})\end{array}$ \\
\hline Waist $(\mathrm{cm})$ & 29,080 & 2694 & & & \\
\hline$\leq 86.0$ & 7206 & 351 & 2.67 & 1 & 1 \\
\hline $86.1-91.0$ & 6891 & 497 & 4.04 & $1.52(1.32-1.74)$ & $1.06(0.92-1.21)$ \\
\hline $91.1-97.0$ & 7907 & 752 & 5.49 & $2.07(1.82-2.35)$ & $1.09(0.96-1.24)$ \\
\hline$\geq 97.1$ & 7076 & 1094 & 9.58 & $3.63(3.22-4.10)$ & $1.40(1.24-1.58)$ \\
\hline $\begin{array}{l}\text { Waist-to-hip } \\
\text { ratio }\end{array}$ & 29,079 & 2694 & & & \\
\hline$\leq 0.86$ & 7324 & 286 & 2.14 & 1 & 1 \\
\hline $0.87-0.89$ & 7214 & 448 & 3.39 & $1.67(1.44--1.94)$ & $1.04(0.89-1.20)$ \\
\hline $0.90-0.93$ & 7237 & 728 & 5.81 & $2.82(2.46-3.24)$ & $1.20(1.05-1.38)$ \\
\hline$\geq 0.94$ & 7304 & 1232 & 10.85 & $5.30(4.65-6.03)$ & $1.47(1.29-1.68)$ \\
\hline BMI $\left(\mathrm{m} / \mathrm{kg}^{2}\right)$ & 29,080 & 2694 & & & \\
\hline$\leq 24.1$ & 7273 & 522 & 4.09 & 1 & 1 \\
\hline $24.2-26.1$ & 7298 & 650 & 5.07 & $1.24(1.11-1.39)$ & $0.99(0.88-1.11)$ \\
\hline $26.2-28.4$ & 7274 & 656 & 5.15 & $1.26(1.12-1.41)$ & $0.93(0.83-1.05)$ \\
\hline$\geq 28.5$ & 7235 & 866 & 7.07 & $1.73(1.56-1.93)$ & $1.20(1.07-1.33)$ \\
\hline ICO & 29,080 & 2694 & & & \\
\hline$\leq 0.48$ & 7291 & 216 & 1.60 & 1 & 1 \\
\hline $0.49-0.51$ & 7241 & 466 & 3.56 & $2.26(1.92-2.65)$ & $1.20(1.02-1.42)$ \\
\hline $0.52-0.55$ & 7261 & 715 & 5.70 & $3.62(3.11-4.22)$ & $1.20(1.03-1.39)$ \\
\hline$\geq 0.65$ & 7287 & 1297 & 11.45 & $7.31(6.33-8.45)$ & $1.54(1.33-1.79)$ \\
\hline eTBF $(\%)$ & 29,080 & 2694 & & & \\
\hline$\leq 16.0$ & 7281 & 200 & 1.47 & 1 & 1 \\
\hline $16.1-19.4$ & 7257 & 392 & 2.97 & $2.04(1.72-2.41)$ & $1.20(1.02-1.42)$ \\
\hline $19.5-23.0$ & 7272 & 655 & 5.17 & $3.58(3.06-4.20)$ & $1.20(1.03-1.39)$ \\
\hline$\geq 23.1$ & 7270 & 1447 & 13.26 & $9.32(8.03-10.81)$ & $1.54(1.33-1.79)$ \\
\hline ABSI & 29,080 & 2694 & & & \\
\hline$\leq 0.75$ & 7269 & 235 & 1.71 & 1 & 1 \\
\hline $0.76-0.78$ & 7271 & 403 & 3.04 & $1.77(1.50-2.08)$ & $0.96(0.82-1.13)$ \\
\hline $0.79-0.80$ & 7270 & 671 & 5.33 & $3.14(2.71-3.65)$ & $1.10(0.94-1.28)$ \\
\hline$\geq 0.81$ & 7270 & 1385 & 12.71 & $7.61(6.62-8.74)$ & $1.38(1.19-1.59)$ \\
\hline
\end{tabular}

$C V$ cardiovascular, $H R$ hazard ratio, $C I$ confidence interval, $W H R$ waist-to-hip ratio, $B M I$ body mass index, $I C O$ index of central obesity, $e T B F$ estimated total body fat, $A B S I$ a body shape index and easy-to-calculate index that may be useful for clinicians for $\mathrm{CV}$ risk estimation.

The relationship between risk for $\mathrm{CV}$ mortality and overweight is complex. However, studies that have evaluated the association between obesity and life expectancy have shown that extreme obesity may shorten life expectancy up to 14 years [17] and that the obesity-associated mortality has increased over the past decades [18-20]. BMI is the most commonly used tool for clinicians to classify obesity. However, acknowledging the already mentioned limitations of BMI, it is debated whether BMI is an appropriate measure to identify obesity related CV risk [21, 22]. A more accurately defined risk score may help the health care provider to emphasise the importance of reduction of weight and body fat [23], and better indices of adiposity than BMI are thus needed. Assessment of fat mass by the gold-standard approach requires imaging techniques, which are impossible to implement in clinical practice due to high cost, radiation exposure, and long scan time. Surrogate indices of total adiposity like eTBF, which is highly correlated with total body fat content as measured by dual $\mathrm{X}$-ray absorptiometry (DXA) [23, 24], is therefore an applicable tool for estimation of $\mathrm{CV}$ mortality risk associated with adiposity.

Previous analyses of non-traditional adiposity indices, including a former analysis of the present cohort with fewer years of follow-up [5], did not evaluate ABSI or eTBF, but in general, these studies support the notion that 
Fig. 1 a-f The risk of cardiovascular death (hazard ratio with $95 \%$ confidence intervals) according to each unit of the adiposity indices, for men and women separately. a Waist circumference, $\mathbf{b}$ body mass index (BMI), c waist-to-hip ratio (WHR), d index of central obesity (ICO), e estimated total body fat (eTBF), and $\mathbf{f}$ a body shape index (ABSI) (blue: men; red: women)
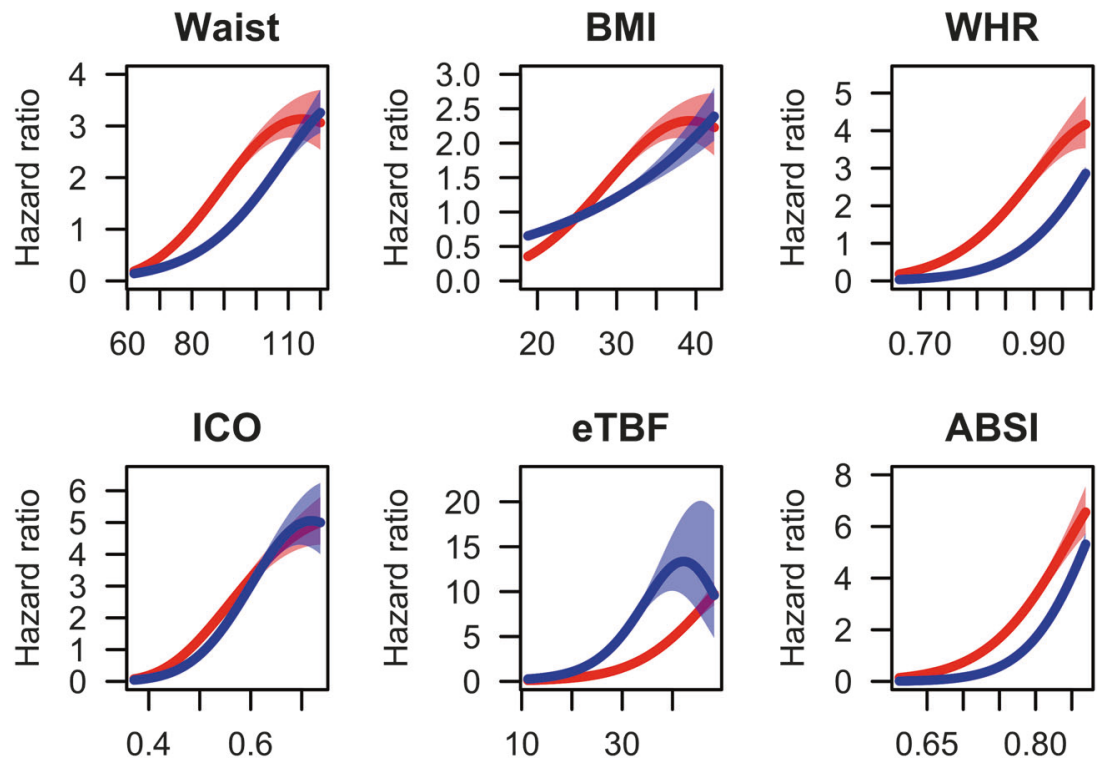

non-traditional indices of obesity are more strongly associated with $\mathrm{CV}$ mortality than BMI $[8,25,26]$.

We found that measures of visceral fat such as WC and WHR, traditionally regarded to be better predictors of mortality than BMI, were weaker discriminators for $\mathrm{CV}$ mortality risk than eTBF. One reason could be that eTBF, unlike the others, is gender specific, and thus incorporates the gender disparity in adipose function [27-30] and distribution [31], that is, women tend to have higher levels of subcutaneous fat for a given BMI or WC [32]. This could also explain the higher mortality risk at lower eTBF levels in men seen in Fig. 1. Further, as the eTBF formula encompasses both WC and weight, it may reflect other important fat depots, for example, epicardial or intramuscular, which are missed when WC, the hip circumference or height alone or in combination are assessed. In accordance with this, a previous study from Iceland demonstrated that the amount of intermuscular fat in the thigh was associated with increased mortality in subjects aged 66-96 years [33]. The finding is in accordance with the present report showing that eTBF was a better discriminator for CV death than ICO in men and likely women (Table 4). However, ICO is a better predictor than BMI [5, 7, 8, 25, 26, 34] and ICO correlates well with the amount of visceral fat tissue by MRI [24]. Another potential explanation for our finding is the possibility that eTBF reflects different cardiometabolic risk than that expressed by the amount of visceral or total body fat, for example, risk related to the relative amount of the two fat compartments or gender. More extensive validation of eTBF in another population is necessary to verify our findings, and to investigate whether reduction of eTBF would translate into a lower CV risk.

The other two non-traditional adiposity indices, ABSI and ICO, were both more strongly associated with CV death than the established measures (BMI, WC and WHR). ABSI was derived from a US general population sample and incorporates $\mathrm{WC}$ and $\mathrm{BMI}$, and thus requires the measurement of height, unlike eTBF [10]. High ABSI indicates that $\mathrm{WC}$ is higher than expected for a given height and weight and suggests abdominal obesity. We found that ABSI seemed to discriminate better than ICO in men, whereas in women, ICO was better than ABSI, although the confidence intervals were overlapping for both sexes (Table 4). These findings are in line with other studies of ABSI in both elderly [6] and middle-aged populations [35]. A gender disparity of ABSI is also in accordance with previous findings [36]. In men, ABSI was positively correlated to the fat mass index, and negatively correlated to DXA-measured fat-free mass index, whereas in women, ABSI was positively correlated to both fat mass index and fat-free mass index [36]. This discrepancy may reflect the difference in body composition between genders, with a tendency of accumulation of fat centrally in men, and in the glutealfemoral region in women [37], and may explain why ABSI may not be able to identify or discriminate the hazardous abdominal visceral fat from other tissue as well in women as in men.

Age modified the association of all adiposity indices' to $\mathrm{CV}$ mortality risk as indicated in Table $2 \mathrm{a}$ and $2 \mathrm{~b}$ and in the age-strata analysis (Table $3 \mathrm{a}$ and $3 \mathrm{~b}$ ), underscoring that age is a risk modifier, in line with other studies [6, 35, 38]. Nevertheless, also in the elderly, we find a "dose response" between increasing quartiles of all adiposity indices and risk of $\mathrm{CV}$ death, except for BMI. This may be explained by BMI's lacking ability to capture body composition and body fat distribution: as age advances, lean body mass decreases and fat mass increases with a preferential distribution in the abdominal region [39]. 
Table 3a Unadjusted and age-adjusted associations between quartiles of the adiposity indices and CV death stratified by age in women

\begin{tabular}{|c|c|c|c|c|}
\hline \multirow[b]{2}{*}{ Age } & \multicolumn{4}{|l|}{ Women $(n=31,936)$} \\
\hline & $19-59$ years $(n=23,120)$ & $19-59$ years $(n=23,120)$ & $60-79$ years $(n=8816)$ & $60-79$ years $(n=8816)$ \\
\hline Waist circumference $(\mathrm{cm})$ & Unadjusted HR (95\% CI) & Age-adjusted HR (95\% CI) & Unadjusted HR (95\% CI) & Age-adjusted HR $(95 \% \mathrm{CI})$ \\
\hline 1st quartile & 1 & 1 & 1 & 1 \\
\hline 2nd quartile & $1.77(1.14-2.76)$ & $1.24(0.80-1.94)$ & $0.91(0.76-1.11)$ & $0.86(0.71-1.04)$ \\
\hline 3rd quartile & $1.70(1.07-2.69)$ & $0.99(0.62-1.57)$ & $1.13(0.95-1.35)$ & $0.95(0.80-1.13)$ \\
\hline 4th quartile & $3.58(2.35-5.46)$ & $1.75(1.14-2.69)$ & $1.46(1.24-1.73)$ & $1.18(1.00-1.40)$ \\
\hline \multicolumn{5}{|l|}{ WHR } \\
\hline 1st quartile & 1 & 1 & 1 & 1 \\
\hline 2nd quartile & $1.62(1.01-2.60)$ & $1.36(0.85-2.19)$ & $1.33(1.11-1.58)$ & $1.07(0.90-1.28)$ \\
\hline 3rd quartile & $2.05(1.29-3.26)$ & $1.42(0.89-2.25)$ & $1.37(1.16-2.22)$ & $1.05(0.89-1.25)$ \\
\hline 4th quartile & $4.05(2.64-6.22)$ & $2.36(1.53-3.62)$ & $1.89(1.61-2.22)$ & $1.40(1.19-1.64)$ \\
\hline \multicolumn{5}{|l|}{ BMI $\left(\mathrm{kg} / \mathrm{m}^{2}\right)$} \\
\hline 1st quartile & 1 & 1 & 1 & 1 \\
\hline 2nd quartile & $1.59(1.04-2.46)$ & $1.15(0.74-1.77)$ & $0.82(0.70-0.96)$ & $0.84(0.71-0.98)$ \\
\hline 3rd quartile & $1.66(1.07-2.58)$ & $0.96(0.62-1.50)$ & $0.88(0.76-1.02)$ & $0.86(0.74-0.99)$ \\
\hline 4th quartile & $2.89(1.92-4.35)$ & $1.49(0.98-2.25)$ & $1.07(0.93-1.22)$ & $1.02(0.89-1.18)$ \\
\hline \multicolumn{5}{|l|}{$\mathrm{ICO}$} \\
\hline 1st quartile & 1 & 1 & 1 & 1 \\
\hline 2nd quartile & $1.94(1.23-3.08)$ & $1.28(0.80-2.02)$ & $1.00(0.80-1.25)$ & $0.91(0.73-1.13)$ \\
\hline 3rd quartile & $2.57(1.63-4.05)$ & $1.38(0.87-2.19)$ & $1.23(1.01-1.51)$ & $0.95(0.78-1.13)$ \\
\hline 4th quartile & $4.46(2.88-6.89)$ & $1.99(1.28-3.10)$ & $1.67(1.37-2.03)$ & $1.18(0.97-1.43)$ \\
\hline \multicolumn{5}{|l|}{ eTBF (\%) } \\
\hline 1st quartile & 1 & 1 & 1 & 1 \\
\hline 2nd quartile & $2.00(1.23-3.23)$ & $1.38(0.85-2.24)$ & $1.27(1.00-1.61)$ & $1.07(0.84-1.36)$ \\
\hline 3rd quartile & $2.90(1.82-4.63)$ & $1.63(1.02-2.62)$ & $1.41(1.13-1.77)$ & $1.02(0.81-1.28)$ \\
\hline 4th quartile & $5.88(3.75-9.21)$ & $2.67(1.69-4.20)$ & $2.21(1.78-2.75)$ & $1.37(1.10-1.70)$ \\
\hline \multicolumn{5}{|l|}{ ABSI } \\
\hline 1st quartile & 1 & 1 & 1 & 1 \\
\hline 2nd quartile & $1.31(0.82-2.11)$ & $1.06(0.66-1.70)$ & $1.01(0.84-1.22)$ & $0.88(0.73-1.06)$ \\
\hline 3rd quartile & $2.39(1.55-3.69)$ & $1.62(1.05-2.50)$ & $1.27(1.07-1.51)$ & $0.97(0.82-1.15)$ \\
\hline 4th quartile & $3.72(2.44-5.66)$ & $2.16(1.41-3.30)$ & $2.00(1.71-2.35)$ & $1.33(1.13-1.57)$ \\
\hline
\end{tabular}

$C V$ cardiovascular, $H R$ hazard ratio, $C I$ confidence interval, WHR waist-to-hip ratio, BMI body mass index, ICO index of central obesity, $e T B F$ estimated total body fat, $A B S I$ a body shape index

As shown in Figs. 1 and 2, the relationship between all the adiposity indices and risk of $\mathrm{CV}$ death were close to linear up to higher levels of adiposity, in women as well as in men. Interestingly, at higher levels of all adiposity indices, except for BMI in men, the associated risk of CV death seemed to level off. This may potentially be explained by competing risks, "the obesity paradox" [40], or be an artefact due to lower sample size in the higher ranges of adiposity.

The strengths of this study are the large number of participants, the population-based prospective design, the objectively measured body height, weight, and waist and hip circumference and the completeness of the data set, enhancing the generalisability of our results. Furthermore, the homogeneity of the population is of importance, since ethnicity and racial differences in body composition influence the associations of anthropometric measures with $\mathrm{CV}$ outcomes. However, our findings may not be generalised beyond Caucasians, since our dataset does not include African Americans or Asians. The principal limitation of our study, as of other registry-based studies, is the restricted possibility to address all potential confounding factors.

In this population-based study with more than one million person-years of observation, the gender-specific adiposity index eTBF was associated with $\mathrm{CV}$ death in men as well as in women, and more so than other non-traditional and traditional adiposity indices. eTBF reflects the amount of total body fat, is easily calculated and may thus be a suitable clinical tool for assessment of obesity-associated CV risk. 
Table 3b Unadjusted and ageadjusted associations between quartiles of the adiposity indices and $\mathrm{CV}$ death stratified by age in men

\begin{tabular}{|c|c|c|c|c|}
\hline \multirow{2}{*}{$\overline{\text { Age }}$} & \multicolumn{4}{|l|}{ Men $(n=29,080)$} \\
\hline & $\begin{array}{l}19-59 \text { years } \\
(n=21,237)\end{array}$ & $\begin{array}{l}19-59 \text { years } \\
(n=21,237)\end{array}$ & $\begin{array}{l}60-79 \text { years } \\
(n=7843)\end{array}$ & $\begin{array}{l}60-79 \text { years } \\
(n=7843)\end{array}$ \\
\hline $\begin{array}{l}\text { Waist circumference } \\
(\mathrm{cm})\end{array}$ & $\begin{array}{l}\text { Unadjusted HR } \\
(95 \% \mathrm{CI})\end{array}$ & $\begin{array}{l}\text { Age-adjusted HR } \\
(95 \% \text { CI })\end{array}$ & $\begin{array}{l}\text { Unadjusted HR } \\
(95 \% \mathrm{CI})\end{array}$ & $\begin{array}{l}\text { Age-adjusted HR } \\
(95 \% \mathrm{CI})\end{array}$ \\
\hline 1st quartile & 1 & 1 & 1 & 1 \\
\hline 2nd quartile & $1.72(1.25-2.37)$ & $1.20(0.87-1.64)$ & $1.02(0.88-1.19)$ & $1.03(0.88-1.20)$ \\
\hline 3rd quartile & $2.01(1.48-2.74)$ & $1.20(0.88-1.63)$ & $1.15(1.00-1.32)$ & $1.06(0.92-1.22)$ \\
\hline 4th quartile & $4.12(3.09-5.50)$ & $2.10(1.57-2.81)$ & $1.41(1.23-1.61)$ & $1.29(1.13-1.48)$ \\
\hline \multicolumn{5}{|l|}{ WHR } \\
\hline 1st quartile & 1 & 1 & 1 & 1 \\
\hline 2nd quartile & $1.62(1.17-2.25)$ & $1.10(0.79-1.53)$ & $1.06(0.90-1.25)$ & $1.01(0.86-1.20)$ \\
\hline 3rd quartile & $2.76(2.04-3.75)$ & $1.54(1.13-2.09)$ & $1.22(1.04-1.42)$ & $1.13(0.96-1.32)$ \\
\hline 4th quartile & $4.58(3.40-6.15)$ & $1.97(1.46-2.67)$ & $1.59(1.38-1.84)$ & $1.37(1.18-1.59)$ \\
\hline \multicolumn{5}{|l|}{ BMI $\left(\mathrm{kg} / \mathrm{m}^{2}\right)$} \\
\hline 1st quartile & 1 & 1 & 1 & 1 \\
\hline 2nd quartile & $1.42(1.04-1.92)$ & $1.09(0.80-1.47)$ & $0.97(0.86-1.10)$ & $0.97(0.86-1.10)$ \\
\hline 3rd quartile & $1.59(1.18-2.13)$ & $1.07(0.80-1.44)$ & $0.87(0.77-0.98)$ & $0.91(0.80-1.03)$ \\
\hline 4th quartile & $2.65(2.02-3.49)$ & $1.67(1.27-2.20)$ & $1.06(0.94-1.19)$ & $1.12(0.99-1.26)$ \\
\hline \multicolumn{5}{|l|}{$\mathrm{ICO}$} \\
\hline 1st quartile & 1 & 1 & 1 & 1 \\
\hline 2nd quartile & $2.58(1.85-3.62)$ & $1.64(1.17-2.30)$ & $1.04(0.86-1.25)$ & $1.08(0.89-1.29)$ \\
\hline 3rd quartile & $2.83(2.01-3.97)$ & $1.44(1.02-2.03)$ & $1.20(1.01-1.42)$ & $1.09(0.92-1.29)$ \\
\hline 4th quartile & $6.65(4.84-9.12)$ & $2.86(2.08-3.95)$ & $1.57(1.34-1.85)$ & $1.31(1.11-1.54)$ \\
\hline \multicolumn{5}{|l|}{ eTBF (\%) } \\
\hline 1st quartile & 1 & 1 & 1 & 1 \\
\hline 2nd quartile & $2.34(1.67-3.26)$ & $1.53(1.09-2.14)$ & $1.04(0.85-1.27)$ & $1.08(0.89-1.32)$ \\
\hline 3rd quartile & $3.32(2.40-4.58)$ & $1.71(1.23-2.37)$ & $1.20(1.00-1.44)$ & $1.10(0.92-1.32)$ \\
\hline 4th quartile & $6.45(4.70-8.86)$ & $2.58(1.87-3.56)$ & $1.83(1.54-2.17)$ & $1.42(1.20-1.68)$ \\
\hline \multicolumn{5}{|l|}{ ABSI } \\
\hline 1st quartile & 1 & 1 & 1 & 1 \\
\hline 2nd quartile & $1.25(0.94-1.66)$ & $0.94(0.71-1.26)$ & $1.07(0.88-1.31)$ & $0.95(0.78-1.16)$ \\
\hline 3rd quartile & $1.78(1.35-2.34)$ & $1.10(0.83-1.45)$ & $1.34(1.12-1.61)$ & $1.08(0.90-1.30)$ \\
\hline 4th quartile & $3.15(2.41-4.12)$ & $1.62(1.23-2.12)$ & $2.00(1.68-2.37)$ & $1.32(1.11-1.58)$ \\
\hline
\end{tabular}

$C V$ cardiovascular, $H R$ hazard ratio, $C I$ confidence interval, $W H R$ waist-to-hip ratio, $B M I$ body mass index, $I C O$ gindex of central obesity, $e T B F$ estimated total body fat, $A B S I$ a body shape index
Table $4 C$-statistics for unadjusted models of the traditional and nontraditional adiposity indices in prediction of $\mathrm{CV}$ death

\begin{tabular}{lll}
\hline & \multicolumn{2}{l}{$C$-statistics $(95 \%$ confidence interval) } \\
\cline { 2 - 3 } & Women & Men \\
\hline eTBF & $0.725(0.713-0.737)$ & $0.711(0.701-0.721)$ \\
ICO & $0.704(0.692-0.716)$ & $0.682(0.672-0.692)$ \\
ABSI & $0.690(0.678-0.702)$ & $0.700(0.690-0.710)$ \\
Waist circumference & $0.663(0.651-0.675)$ & $0.626(0.616-0.636)$ \\
WHR & $0.659(0.647-0.671)$ & $0.664(0.654-0.674)$ \\
BMI & $0.622(0.610-0.634)$ & $0.551(0.541-0.562)$ \\
\hline
\end{tabular}

WHR waist-to-hip ratio, $B M I$ body mass index, $I C O$ index of central obesity, $e T B F$ estimated total body fat, $A B S I$ a body shape index

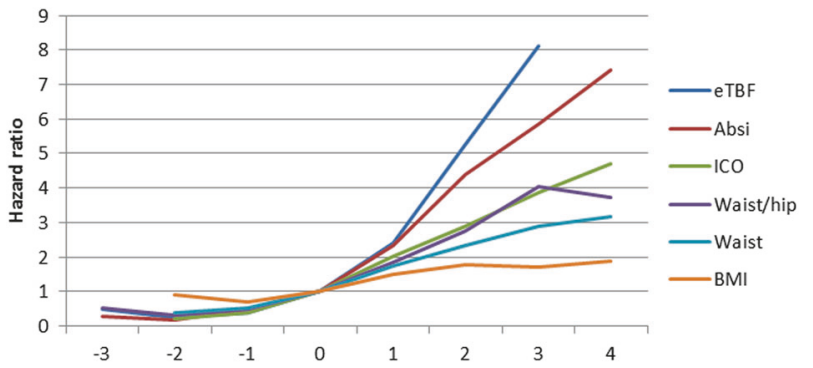

Fig. 2 The risk of cardiovascular death (hazard ratio) according to standardised adiposity indices (standardised by sex-specific $z$-scores of each adiposity index). WHR: waist-to-hip ratio, BMI: body mass index, ICO: index of central obesity, eTBF: estimated total body fat, ABSI: a body shape index 
Acknowledgements Nord-Trøndelag Health Study (the HUNT Study) is a collaboration between HUNT Research Centre (Faculty of Medicine and Health Sciences, Norwegian University of Science and Technology (NTNU)), Nord-Trøndelag County Council, Central Norway Regional Health Authority and the Norwegian Institute of Public Health. We are indebted to the participants of the HUNT Study and the management of the study for using these data.

Funding Boehringer Ingelheim Norway KS paid for the data access.

Author contributions OEJ, KIB, HLG and APO designed the study. APO, CS and JMG performed the statistical analyses and had full access to the database. All authors contributed in the discussion of the output and results. APO drafted the manuscript. All authors gave input and participated in developing the final version of the manuscript.

\section{Compliance with ethical standards}

Conflict of interest APO and OEJ are employed by Boehringer Ingelheim. KIB has received grants to his institution for lectures and consulting from Novo Nordisk, Sanofi, Lilly, Boehringer Ingelheim, AstraZeneca and MSD. HLG has received grants for lectures or consulted for Novo Nordisk, Sanofi, Boehringer Ingelheim, AstraZeneca and MSD. MRB has received grants to her institution for lectures and consulting from Sanofi and AstraZeneca. The other authors declare that they have no conflict of interest.

Publisher's note: Springer Nature remains neutral with regard to jurisdictional claims in published maps and institutional affiliations.

Open Access This article is licensed under a Creative Commons Attribution 4.0 International License, which permits use, sharing, adaptation, distribution and reproduction in any medium or format, as long as you give appropriate credit to the original author(s) and the source, provide a link to the Creative Commons license, and indicate if changes were made. The images or other third party material in this article are included in the article's Creative Commons license, unless indicated otherwise in a credit line to the material. If material is not included in the article's Creative Commons license and your intended use is not permitted by statutory regulation or exceeds the permitted use, you will need to obtain permission directly from the copyright holder. To view a copy of this license, visit http://creativecommons. org/licenses/by/4.0/.

\section{References}

1. Afshin A, Forouzanfar MH, Reitsma MB, Sur P, Estep K, Lee A, et al. Health effects of overweight and obesity in 195 countries over 25 years. N Engl J Med. 2017;377:13-27.

2. Piepoli MF, Hoes AW, Agewall S, Albus C, Brotons C, Catapano AL, et al. 2016 European Guidelines on cardiovascular disease prevention in clinical practice: The Sixth Joint Task Force of the European Society of Cardiology and Other Societies on Cardiovascular Disease Prevention in Clinical Practice (constituted by representatives of 10 societies and by invited experts). Developed with the special contribution of the European Association for Cardiovascular Prevention \& Rehabilitation (EACPR). Eur Heart J. 2016;37:2315-81.

3. WHO. Physical status: the use and interpretation of anthropometry. Report of a WHO Expert Committee. World Health Organisation Technical Report Series. Geneva: World Health Organization; 1995. p. 1-452.
4. Despres JP, Lemieux I, Bergeron J, Pibarot P, Mathieu P, Larose $\mathrm{E}$, et al. Abdominal obesity and the metabolic syndrome: contribution to global cardiometabolic risk. Arterioscler Thromb Vasc Biol. 2008;28:1039-49.

5. Petursson H, Sigurdsson JA, Bengtsson C, Nilsen TI, Getz L. Body configuration as a predictor of mortality: comparison of five anthropometric measures in a 12 year follow-up of the Norwegian HUNT 2 study. PLoS ONE. 2011;6:e26621.

6. Dhana K, Kavousi M, Ikram MA, Tiemeier HW, Hofman A, Franco $\mathrm{OH}$. Body shape index in comparison with other anthropometric measures in prediction of total and cause-specific mortality. J Epidemiol Community Health. 2016;70:90-6.

7. Schneider HJ, Friedrich N, Klotsche J, Pieper L, Nauck M, John $\mathrm{U}$, et al. The predictive value of different measures of obesity for incident cardiovascular events and mortality. J Clin Endocrinol Metab. 2010;95:1777-85.

8. Carlsson AC, Riserus U, Engstrom G, Arnlov J, Melander O, Leander K, et al. Novel and established anthropometric measures and the prediction of incident cardiovascular disease: a cohort study. Int J Obes (Lond). 2013;37:1579-85.

9. Parikh RM, Joshi SR, Menon PS, Shah NS. Index of central obesity-a novel parameter. Med Hypotheses. 2007;68:1272-5.

10. Krakauer NY, Krakauer JC. A new body shape index predicts mortality hazard independently of body mass index. PLoS ONE. 2012;7:e39504.

11. Wilmore JH, Behnke AR. An anthropometric estimation of body density and lean body weight in young men. J Appl Physiol. 1969;27:25-31.

12. Wilmore JH, Behnke AR. An anthropometric estimation of body density and lean body weight in young women. Am J Clin Nutr. 1970;23:267-74

13. Krokstad S, Langhammer A, Hveem K, Holmen TL, Midthjell K, Stene TR, et al. Cohort profile: The HUNT study, Norway. Int J Epidemiol. 2013;42:968-77.

14. Holmen J, Midthjell K, Krüger $\varnothing$, Langhammer A, Holmen TL, Bratberg GH, et al. The Nord-Trøndelag Health Study 1995-97 (HUNT 2): objectives, contents, methods and participation. Norsk Epidemiolo. 2003;13:19-32.

15. Pencina MJ, D'Agostino RB Sr., D'Agostino RB Jr., Vasan RS. Evaluating the added predictive ability of a new marker: from area under the ROC curve to reclassification and beyond. Stat Med. 2008;27:157-72. discussion 207-12.

16. Pencina MJ, D’Agostino RB. Overall $\mathrm{C}$ as a measure of discrimination in survival analysis: model specific population value and confidence interval estimation. Stat Med. 2004;23:2109-23.

17. Kitahara CM, Flint AJ, Berrington de Gonzalez A, Bernstein L, Brotzman M, MacInnis RJ, et al. Association between class III obesity (BMI of $40-59 \mathrm{~kg} / \mathrm{m} 2$ ) and mortality: a pooled analysis of 20 prospective studies. PLoS Med. 2014;11:e1001673.

18. D'Souza MJ, Wentzien DE, Bautista RC, Gross CC. Investigation of obesity-related mortality rates in Delaware. Am. J. Health Sci. 2017;8:19-32.

19. Dhana K, Nano J, Ligthart S, Peeters A, Hofman A, Nusselder W, et al. Obesity and life expectancy with and without diabetes in adults aged 55 years and older in the netherlands: a prospective cohort study. PLoS Med. 2016;13:e1002086.

20. Olshansky SJ, Passaro DJ, Hershow RC, Layden J, Carnes BA, Brody J, et al. A potential decline in life expectancy in the United States in the 21st century. N Engl J Med. 2005;352:1138-45.

21. Ashwell M, Gunn P, Gibson S. Waist-to-height ratio is a better screening tool than waist circumference and BMI for adult cardiometabolic risk factors: systematic review and meta-analysis. Obesity Rev. 2012;13:275-86.

22. Pischon T, Boeing H, Hoffmann K, Bergmann M, Schulze MB, Overvad K, et al. General and abdominal adiposity and risk of death in Europe. N Engl J Med. 2008;359:2105-20. 
23. Vega GL, Adams-Huet B, Peshock R, Willett D, Shah B, Grundy SM. Influence of body fat content and distribution on variation in metabolic risk. J Clin Endocrinol Metab. 2006;91:4459-66.

24. Neeland IJ, McGuire DK, Eliasson B, Ridderstrale M, Zeller C, Woerle HJ, et al. Comparison of adipose distribution indices with gold standard body composition assessments in the EMPA-REG H2H SU Trial: a body composition sub-study. Diabetes Ther. 2015;6:635-42.

25. Lee CM, Huxley RR, Wildman RP, Woodward M. Indices of abdominal obesity are better discriminators of cardiovascular risk factors than BMI: a meta-analysis. J Clin Epidemiol. 2008;61: 646-53.

26. Ashwell M, Mayhew L, Richardson J, Rickayzen B. Waist-toheight ratio is more predictive of years of life lost than body mass index. PLoS ONE. 2014;9:e103483.

27. Law J, Bloor I, Budge H, Symonds ME. The influence of sex steroids on adipose tissue growth and function. Horm Mol Biol Clin Invest. 2014;19:13-24.

28. Bloor ID, Symonds ME. Sexual dimorphism in white and brown adipose tissue with obesity and inflammation. Horm Behav. 2014;66:95-103.

29. Karastergiou K, Smith SR, Greenberg AS, Fried SK. Sex differences in human adipose tissues - the biology of pear shape. Biol Sex Differ. 2012;3:13.

30. Fried SK, Lee MJ, Karastergiou K. Shaping fat distribution: new insights into the molecular determinants of depot- and sexdependent adipose biology. Obesity (Silver Spring). 2015;23: 1345-52.

31. Toth MJ, Tchernof A, Sites CK, Poehlman ET. Menopause-related changes in body fat distribution. Ann NY Acad Sci. 2000;904:502-6.

32. Camhi SM, Bray GA, Bouchard C, Greenway FL, Johnson WD, Newton RL, et al. The relationship of waist circumference and
BMI to visceral, subcutaneous, and total body fat: sex and race differences. Obesity (Silver Spring). 2011;19:402-8.

33. Koster A, Murphy RA, Eiriksdottir G, Aspelund T, Sigurdsson S, Lang TF, et al. Fat distribution and mortality: the AGES-Reykjavik Study. Obesity (Silver Spring). 2015;23: 893-7.

34. Cox BD, Whichelow M. Ratio of waist circumference to height is better predictor of death than body mass index. BMJ. 1996;313:1487.

35. Sardarinia M, Ansari R, Azizi F, Hadaegh F, Bozorgmanesh M. Mortality prediction of a body shape index versus traditional anthropometric measures in an Iranian population: Tehran Lipid and Glucose Study. Nutrition (Burbank, Los Angeles County, Calif). 2017;33:105-12.

36. Dhana K, Koolhas C, Schoufour J, Rivadeneira F, Hofman A, Kavousi M, et al. Association of anthropometric measures with fat and fat-free mass in the elderly: The Rotterdam study. Maturitas. 2016;88:96-100.

37. Seidell JC, Cigolini M, Charzewska J, Ellsinger BM, Bjorntorp P, Hautvast JG, et al. Fat distribution and gender differences in serum lipids in men and women from four European communities. Atherosclerosis. 1991;87:203-10.

38. Dalton M, Cameron AJ, Zimmet PZ, Shaw JE, Jolley D, Dunstan DW, et al. Waist circumference, waist-hip ratio and body mass index and their correlation with cardiovascular disease risk factors in Australian adults. J Intern Med. 2003;254:555-63.

39. Kuk JL, Saunders TJ, Davidson LE, Ross R. Age-related changes in total and regional fat distribution. Ageing Res Rev. 2009;8: 339-48.

40. Lavie CJ, De Schutter A, Milani RV. Healthy obese versus unhealthy lean: the obesity paradox. Nat Rev Endocrinol. 2015; 11:55-62. 